\title{
Pod1 is involved in the sexual differentiation and gonadal development of the Nile tilapia
}

\author{
LI JianZhong $^{1,2^{*}}$ LIU ShaoJun $^{1} \&$ NAGAHAMA Yoshitaka ${ }^{2}$ \\ ${ }^{1}$ Key Laboratory of Protein Chemistry and Developmental Biology of Ministry of Education, College of Life Sciences, Hunan Normal Univer- \\ sity, Changsha 410081, China; \\ ${ }^{2}$ Laboratory of Reproductive Biology, National Institute for Basic Biology, Okazaki 444-8585, Japan
}

Received April 20, 2011; accepted October 22, 2011

\begin{abstract}
Pod1 is a member of the basic helix-loop-helix (bHLH) family of transcription factors that have been implicated in the regulation of sexual differentiation and gonadal development in mammals. However, to date, little is known about the role of Pod1 in nonmammalian vertebrate gonadogenesis. We cloned and characterized the Podl gene from tilapia. The tilapia Podl gene contains an open reading frame (ORF) of 525 nucleotides which potentially codes for a protein with 174 amino acids. Sequence alignment revealed that the deduced tilapia protein sequence shared high homology (79.5\% to 90.5\%) with the Pod1 sequences of other vertebrates. The tissue distribution of Podl revealed by RT-PCR showed that it had varied expression patterns in adult tilapia. In situ hybridization was performed to examine the temporal and spatial expression patterns of Pod 1 during tilapia sexual differentiation and gonadal development. In the undifferentiated gonad, Podl was expressed in the somatic cells of both sexes. Subsequently, Pod1 expression in tilapia persisted in differentiated juvenile and adult ovary and testis. Our data indicate for the first time that Pod 1 is not only necessary for the onset of sexual differentiation, but also plays an important role in gonadal development in the teleost.
\end{abstract}

Pod1, somatic cells, sexual differentiation, gonadal development, tilapia

Citation: $\quad$ Li J Z, Liu S J, Nagahama Y. Pod1 is involved in the sexual differentiation and gonadal development of the Nile tilapia. Sci China Life Sci, 2011, 54: 1005-1010, doi: 10.1007/s11427-011-4240-4

The basic helix-loop-helix (bHLH) family of transcription factors to which Pod1 belongs, has been shown to play important roles in regulating cell proliferation and differentiation in many cell types including lymphocytes, myocytes, and neurons $[1,2]$. The bHLH transcription factors bind to $\mathrm{E}$ box regions (CANNTG) in the control regions of target genes and are classified into two groups, ubiquitous class A and tissue-specific class B [1].

Pod1, also known as epicardin, capsulin, or transcription factor 21 , is most highly expressed in embryonic mesodermal cells including proepicardial cells of the heart, mesenchymal cells in areas of tubular epithelial development in

*Corresponding author (email: ljzhong @ hunnu.edu.cn) the kidney, lung and gastrointestinal tract, and in visceral smooth muscle [3-7]. Pod1 knockout mice die in the perinatal period from lung, kidney, and cardiac defects and also display gastric and splenic defects, suggesting a complex role for Pod1 in embryogenesis [8-10].

Pod1 was the first class B bHLH transcription factor whose expression pattern was reported to be sex- and stage-dependent during gonadogenesis in mammals [11]. Also, Podl appears to be one of the first genes to be expressed in the mesodermal cells that later form the gonad. Pod1 is essential for normal development of the testes and ovaries, and hence for sexual differentiation. The gonads of Pod1 knockout mice were markedly hypoplastic, and the urogenital tracts of both XX and XY mice remained indis- 
tinguishable throughout embryogenesis [12]. Pod1 transcriptionally repressed steroidogenic factor 1 (Sf1/Nr5a1/ Ad4BP), an orphan nuclear receptor that regulates the expression of multiple genes that mediate sexual differentiation $[11,12]$. Furthermore, Pod1 has been reported to control androgen receptor (AR) transcription and play an important role in the development and function of the testis $[13,14]$. Although the role of Pod1 in mammalian gonadogenesis has been demonstrated [11-14], to date, little is known about the possible role of Pod1 in nonmammalian vertebrate sexual differentiation and gonadal development.

Nile tilapia, Oreochromis niloticus, a gonochoristic teleost fish with an XX-XY sex-determining system, provides an excellent model for studying sexual differentiation [15]. In this species, sex reversal is readily inducible using hormones, and sex-reversed males (XX) and supermales (YY) have been produced. Consequently, all-male or all-female populations can easily be produced using these males. As the first step towards elucidating the function of Podl in fish reproduction, we cloned and identified the Pod1 gene from tilapia, and explored its temporal and spatial expression patterns during the tilapia reproductive cycle. Our data suggest for the first time that Pod1 is involved in fish sexual differentiation and gonadal development.

\section{Materials and methods}

\subsection{Animals}

Nile tilapia (Oreochromis niloticus) were reared in fresh water in re-circulating 500-L freshwater tanks, and maintained at ambient temperature $\left(26^{\circ} \mathrm{C}\right)$ under natural light conditions. All genetic female (XX) and male (XY) fry were obtained by artificial fertilization of eggs from a normal female (XX) and sperms from a sex-reversed male $(\mathrm{XX})$, and eggs from a normal female (XX) and sperms from a super male (YY), respectively, as described in a previous report [15]. Fertilized eggs were cultured in re-circulating water at $26^{\circ} \mathrm{C}$. All experiments conformed to the Guide for Care and Use of Laboratory Animals and were approved by the Institutional Committee of Laboratory Animal Experimentation (Hunan Normal University, China).

\subsection{Molecular cloning of Pod1 from tilapia}

Total RNA was isolated from the tilapia testis with the RNeasy Kit (Qiagen, Germany). The first strand cDNA was synthesized using oligo-dT18 primer with Superscript III Kit (Invitrogen, USA). The open reading frame (ORF) of Podl cDNA was cloned by reverse transcription-PCR (RT-PCR) with gene-specific primers designed from the conserved regions of other vertebrate Pod1 sequences. The primers were forward, 5'-ATGTCCACCGGGTCTCTCAGCGA-3'; reverse, 5'-TCAGGACGCAGTGGTTCCGCACA-3'. The PCR cycle was $94^{\circ} \mathrm{C}, 30 \mathrm{~s} ; 65^{\circ} \mathrm{C}, 30 \mathrm{~s}$; and $72^{\circ} \mathrm{C}$,
1 min for 35 cycles.

\subsection{Phylogenetic analysis}

The deduced protein sequence of the tilapia Pod1 was compared to other representative vertebrate species, including tetraodon (Tetraodon nigroviridis), salmo (Salmo salar), zebrafish (Danio rerio), human (Homo sapiens), chicken (Gallus gallus), and frog (Xenopus tropicalis). All the sequences were subjected to a BLAST analysis (http://www. ncbi.gov/blast). Multiple sequence alignment of the tilapia Pod1 with the Pod1 sequences from other species was performed using ClustalW (2.0) software (http://www.ebi.ac. uk/clustalw). A phylogenetic tree for the Pod1 proteins in vertebrates was constructed with the MEGA 4.1 package using the neighbor-joining method. Bootstrap values based on 10000 replicates were proven to support each other.

\subsection{RT-PCR}

Total RNA was isolated from various tissues of adult tilapia with the Qiagen RNeasy Kit (Qiagen) according to the manufacturer's protocol. The first strand cDNA was synthesized using oligo-dT18 primer with Superscript III Kit (Invitrogen). RT-PCR was employed to check the expression of Pod1. The $\beta$-actin gene served as a positive control to confirm amplification of the cDNA pool in all samples. PCR products were analyzed by $1.5 \%$ agarose gel and stained with ethidium bromide. RT-PCR experiments were replicated 3-5 times.

\subsection{In situ hybridization}

The trunks from tilapia fry 5 to 10 days after hatching (dah) were dissected out and fixed in $4 \%$ paraformaldehyde (PFA) in $0.1 \mathrm{~mol} \mathrm{~L}^{-1}$ phosphate buffer (PB) at $4^{\circ} \mathrm{C}$ overnight. Gonads of 20-210 dah fish were removed and fixed in $4 \%$ PFA. After fixation, gonads were embedded in paraffin. Cross-sections were cut to $5 \mu \mathrm{m}$. Sense and antisense digoxigenin (DIG)-labeled RNA probes were transcribed in vitro using an RNA labeling kit (Roche, Germany). In situ hybridization was performed as follows: sections were deparaffinized, hydrated and treated with proteinase $\mathrm{K}$ (Roche, $10 \mathrm{mg} \mathrm{mL}^{-1}$ ) and then hybridized with the sense or antisense DIG-labeled RNA probe at $60^{\circ} \mathrm{C}$ for $18-24 \mathrm{~h}$. The hybridization signals were detected using alkaline phosphatase-conjugated anti-DIG antibody (Roche, Germany) and NBT as the chromogen.

\section{Results and discussion}

\subsection{Tilapia Pod1 gene sequence and phylogenetic analy- sis}

The Podl cDNA was cloned from tilapia adult testis by 
RT-PCR. The 525 bp long isolated open reading frame (ORF) of the tilapia Podl cDNA (GenBank ID: JF809818) encodes a putative protein of 174 amino acids.

The multiple sequence alignment of the tilapia Pod1 with other representative vertebrate species is shown in Figure 1. The tilapia Pod1 protein shares the greatest homology with the Pod1 from tetraodon $(90.5 \%)$, followed by zebrafish (88.6\%), salmo (86.1\%), chicken (82.5\%), human (81.9\%), and frog $(79.5 \%)$.

In the bHLH region, the tilapia Pod1 protein sequence showed $96.4 \%$ identity with the other vertebrate Pod1 homologues (Figure 1). Based on the alignment results, a phylogenetic tree of the Pod1 protein sequences was constructed using the neighbor-joining method (Figure 2).

\subsection{The tissue distribution pattern of Pod1}

RT-PCR analysis was performed to examine the tissue distribution pattern of Podl in adult tilapia. As shown in Figure 3, the tilapia Podl gene was expressed predominantly in spleen, then in ovary, kidney, heart, testis, and brain. The expression of Podl was not detected in liver or gill.

In adult mice, Podl was expressed in the lung, ovary, spleen, kidney, intestine and uterus [4]. In adult frogs, expression of Podl was highest in the rectum and the spleen, with significant expression in the duodenum, heart, kidney, lungs, pancreas, skin, liver and muscle [16]. Our results showed that the tilapia Podl gene was also expressed in a wide variety of extragonadal tissues where it may act as a critical regulator of cell-specific gene expression.

\begin{tabular}{|c|c|}
\hline Tilapia & MSTGSLSDVDD----ELLDGILKFGSSGKDS---NESTEESSNGEGSCANEERRETPGKK 53 \\
\hline Tetraodon & MSTGSLSDVDD----ELLDGILKFGSSGKDS---NESAEESSNCEG--AN----DAPAKK 47 \\
\hline Salmo & MSTGSLSDFDD----EVLDGILKFGSSGKDSGTSNESTEESSNCEGGSAN--DKAAPGKK 54 \\
\hline Zebrafish & MSTGS ISDVDEFHESELLDGLPKFGS-GKDPGTSNESTEDSSNCEGASVS----ECTGKR 55 \\
\hline Human & MSTGSLSDVEDLQEVEMLECDGLKMDSNKEFVTSNESTEESSNCENGSPQK-GRGGLGKR 59 \\
\hline Chicken & MSTGSLSDVEDLQEVEMLDCDGLKMDSNKEFVTSNESTEESSNCETGSPQK-GRGGLGKR 59 \\
\hline \multirow[t]{2}{*}{ Frog } & MSTGSLSDVEDFQDMEMLECDGIKLDPNKEFGISNDSNEESSTCDNGSPKK-GRGTSGKR 59 \\
\hline & 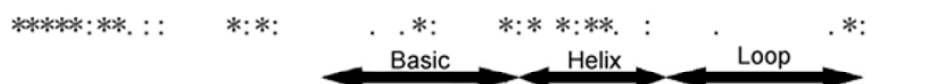 \\
\hline Tilapia & RKTT-SRKTAPKGVAQQEGKQVQRNAANARERARYRVLSKAFSRLKTSLPWVPPDTKLSK 112 \\
\hline Tetraodon & RKSA-SRKSAAKGVAQQESKHVQRNAANARERARMRVLSKAFSRLKTTLPWVPPDTKLSK 106 \\
\hline Salmo & RKTA-PNSVAHEGCG----KPVQRNAANARERARMRVLSKAFSRLKMTLPWVPPDTKLSK 109 \\
\hline Zebrafish & RKSANMRRSAPNGVAQ-EGKQVQRNAANARERARYRVLSKAFSRLKTTLPWVPPDTKLSK 114 \\
\hline Human & RKAP-TKKSPLSGVSQ-EGKQVQRNAANARERARYRVLSKAFSRLKTTLPWVPPDTKLSK 117 \\
\hline Chicken & RKAP-TKKSPLSGVSQ-EGKQVQRNAANARERARYRVLSKAFSRLKTTLPWVPPDTKLSK 117 \\
\hline \multirow[t]{2}{*}{ Frog } & RKAS-SKKSPLGTINQ-EGKQVQRNAANARERARYRVLSKAFSRLKTTLPWVPPDTKLSK 117 \\
\hline & $\longrightarrow$ L \\
\hline Tilapia & LDTLRLASSYIAHLRQILANDKYENGYIHPVNLTWPFMVAGKPENDLKEMLNSTRLCGTT 172 \\
\hline Tetraodon & LDTLRLASSYIAHLRQILANDKYENGFIHPVNLTWPFMVAGKPENDLKEMLNTTRLCGTT 166 \\
\hline Salmo & LDTLRLASSYIAHLRQLLANDKYENGYNHPVNLTWPFMVAGKPENDLKELFNTTRLCGTT 169 \\
\hline Zebrafish & LDTLRLASSYIAHLRQILANDKYENGYIHPVNLTWPFMVAGKPENELKEMLNSTRLCGTT 174 \\
\hline Human & LDTLRLASSYIAHLRQILANDKYENGYIHPVNLTWPFMVAGKPESDLKEVVTASRLOGTT 177 \\
\hline Chicken & LDTLRLASSYIAHLRQILANDKYENGYIHPVNLTWPFMVAGKPENDLKEVVTASRLCGTT 177 \\
\hline Frog & $\begin{array}{l}\text { LDTLRLASSYIAHLRQILANDKYENGYIHPVNLTWPFMVAGKPENDLKEVVSTSRLCGPT } 177 \\
* * * * * * * * * * * * * * * * * * * * * * * * * * * *: * * * * * * * * * * * * * * * * ; * ; *: \ldots: ; * * * * *\end{array}$ \\
\hline Tilapia & AS 174 \\
\hline Tetraodon & AS 168 \\
\hline Salmo & AS 171 \\
\hline Zebrafish & AS 176 \\
\hline Human & AS 179 \\
\hline Chicken & AS 179 \\
\hline \multirow[t]{2}{*}{ Frog } & AS 179 \\
\hline & $* *$ \\
\hline
\end{tabular}

Figure 1 Alignment of predicted Pod1 protein sequences from tilapia and other species. Pod1 sequences contain a bHLH region. Asterisks (*) under the multiple sequence alignment indicate identical amino acids. The symbols (:) and (.) denote conservative or semi-conservative substitutions, respectively. GenBank IDs for the sequences used in the alignment: tilapia, JF809818; tetraodon, CAG09096; salmo, ACI68100; zebrafish, NP_001032770; human, NP_003197; chicken, XP_419734; frog, NP_001085957. 


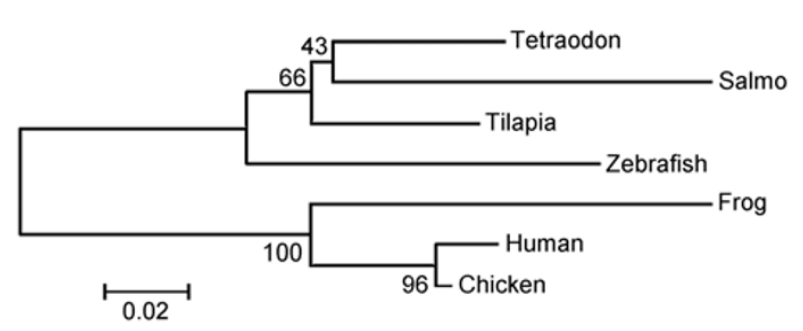

Figure 2 The phylogenetic tree of Pod1 protein was constructed by the MEGA 4.1 program using the neighbor-joining method. The scale bar represents a genetic distance of 0.02 amino acid substitutions per site.

\subsection{Temporal and spatial expression patterns of Pod1}

Previous studies have indicated that tilapia primordial germ cells (PGCs) migrated into the gonadal anlagen 3 dah [15]. Thereafter, the germ cell numbers did not change significantly in either sex from 5 to 8 dah. The $\mathrm{XX}$ female germ cells continued to proliferate 8 dah, whereas the number of germ cells began to increase 14 dah in XY gonads. Under a light microscope, the first signs of gonadal differentiation appeared in tilapia fry 23-26 dah with the formation of the ovarian cavity (Figure 4C) in XX gonads or the efferent duct (Figure 4D) in XY gonads [15].

To examine the temporal and spatial expression patterns of Podl during tilapia sexual differentiation and gonadal development, we performed in situ hybridization using all-XY male and all-XX female fish. Podl expression was first detected in the somatic cells of both sexes 10 dah (date not shown), earlier than the tilapia morphological gonadal differentiation period. In the undifferentiated gonad, Podl was also expressed in the somatic cells of both sexes 20 dah (Figure 4A and B). Subsequently, Pod1 expression persisted in differentiated juvenile and adult gonads in tilapia (Figure 4A and B). In the adult ovary, Podl was expressed in the granulosa cells (Figure 4E). In adult testis, Podl was expressed in the Sertoli cells (the region marked F1 in Figure $4 \mathrm{~F}$ ) and in the epithelial cells of the efferent duct sperms (the region marked F2 in Figure 4F). In contrast, no signals for Podl were detected in the ovary and testis sections with sense probes (Figure $4 \mathrm{G}$ and $\mathrm{H}$ ). We also did not detect any Podl expression in the germ cells of both male and female during sexual differentiation and gonadal development.

Interestingly, tilapia Dmrt1, doublesex and mab-3 related transcription factor 1 , was also expressed in the epithelial cells of the efferent duct in the adult testis [15]. Pod1 did not show sexual dimorphism before the appearance of gonadal differences, whereas the expression of tilapia Dmrt1 was sexually dimorphic [15]. Tilapia Dmrt1 was first detected in the gonial germ-cell-surrounding cells in XY fry specifically 6 dah. Then, the Dmrt1 signals localized in the Sertoli and epithelial cells comprising the efferent duct during gonadal differentiation. After the induction of XY sex reversal with estrogen, Dmrtl decreased and then disappeared completely. These data suggest that Dmrt1 plays a pivotal role in testicular differentiation, while Pod1 is very important for both male and female differentiation in the teleost.

Pod1 is the first class B bHLH transcription factor reported to exhibit an expression pattern that is sex- and stage-dependent during gonadogenesis in mammals [11]. Ad4BP/SF-1 was also shown to be involved in the later stages of sex differentiation of the gonad through its regulation of steroid hormones and maturation-inducing steroids (MIS). In a co-transfection experiment using cultured cells the overexpression of Pod-1 repressed the expression of a reporter gene that carried the upstream regulatory region of the Ad4BP/SF-1 gene. Furthermore, the forced expression of Pod-1 repressed the expression of Ad4BP/SF-1 in Leydig cell-derived I-10 cells. These results suggest that Pod-1 may play important roles in the development and sex differentiation of the mammalian gonad via transcriptional regulation of Ad4BP/SF-1 [11,12].

Although the role of Pod1 in mammalian gonadogenesis has been demonstrated [11-14], to date, the possible functions of Pod1 in nonmammalian vertebrate sexual differentiation and gonadal development remain to be defined. In the undifferentiated gonads of tilapia, Podl was expressed in the somatic cells of both sexes. Subsequently, Pod1 expression persisted in differentiated juvenile and adult ovary and testis. Regardless of the underlying mechanism, our studies suggest for the first time that Pod1 is involved in sexual differentiation and gonadal development in the fish.

\section{Conclusion}

In summary, we cloned and identified the Podl gene from tilapia. We also investigated the tissue distribution pattern of Podl in tilapia by RT-PCR. We explored the temporal and spatial expression patterns of Podl during the tilapia reproductive cycle. Our data indicate for the first time that

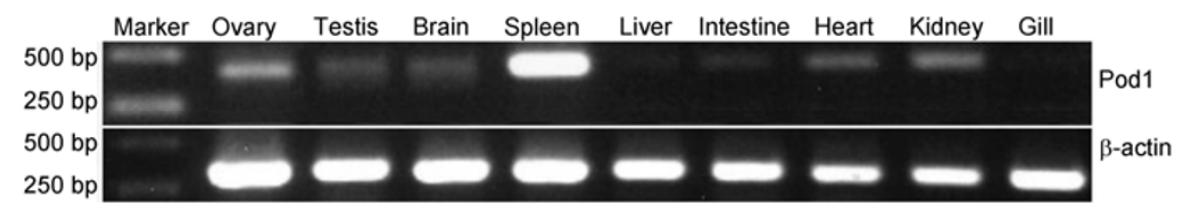

Figure 3 RT-PCR analysis of the tissue distribution pattern of Pod1 in adult tilapia. 

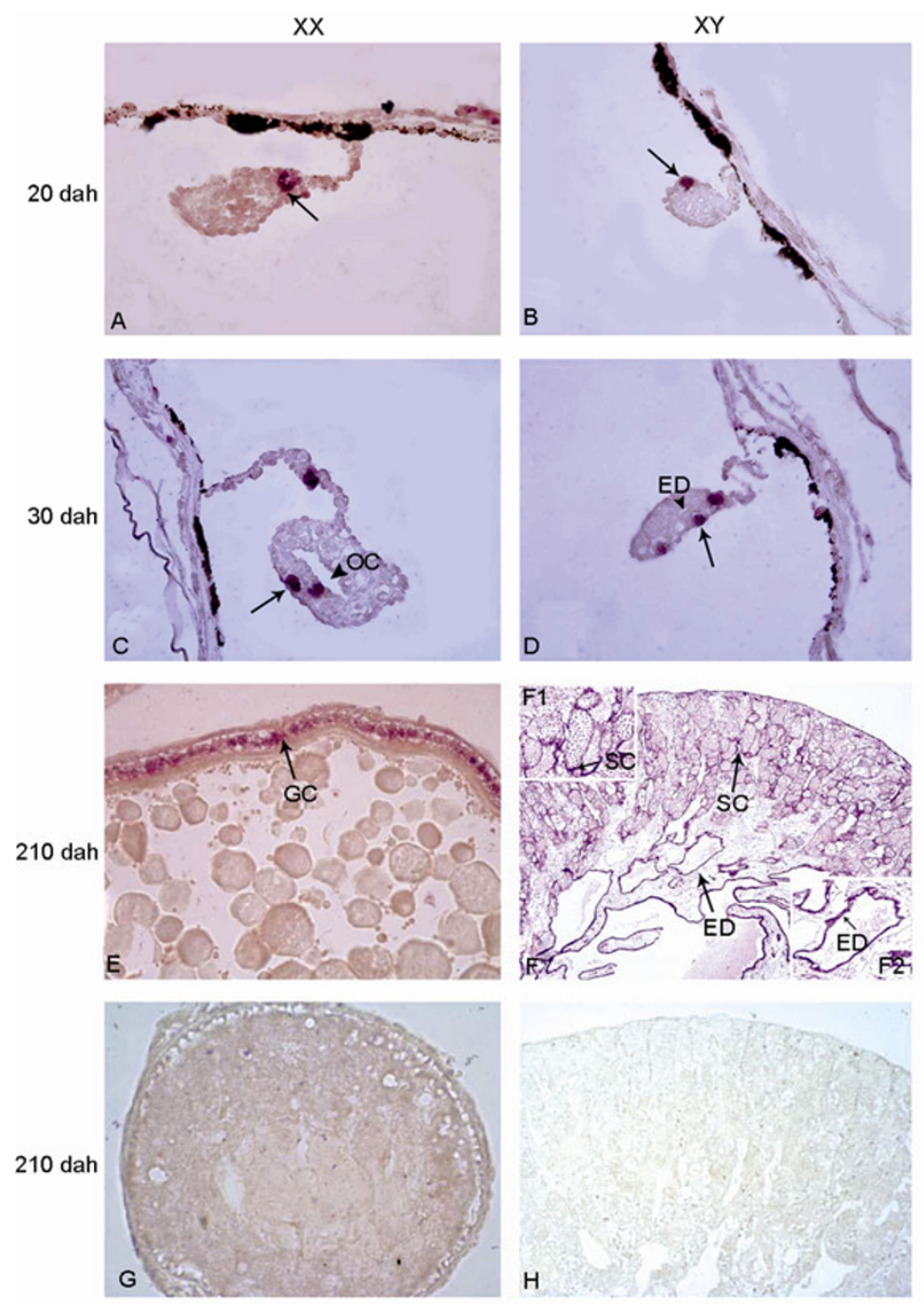

Figure 4 Light microscope images showing tilapia Podl expression during sexual differentiation and gonadal development by in situ hybridization with antisense (A-F) and sense (G and H) probes. A and B, At 20 days after hatching (dah), Podl was expressed in the somatic cells of both sexes. C and D, At 30 dah, Podl expression persisted in the somatic cells of both sexes; the arrows indicate the ovarian cavity (OC) and the efferent duct (ED). E and F, At 210 dah, Podl was expressed in the granulosa cells (GC) of adult ovary and in Sertoli cells (SC) and epithelial cells of the efferent duct (ED) sperms of mature testis. In F, the F1 and F2 regions are magnifications of SC and ED, respectively. $\mathrm{G}$ and $\mathrm{H}$, At 210 dah, no signals for Pod1 were detected in the adult ovary and testis sections with the sense probes. The arrowheads indicate Pod1signals in the XY and XX gonads. Magnification=100× in A-D; 40× in E, and in F1, $\mathrm{F} 2$ in $\mathrm{F}$; and $20 \times$ in $\mathrm{F}, \mathrm{G}$ and $\mathrm{H}$.

Pod1 is not only necessary for the onset of sexual differentiation, but also plays important roles in gonadal development and maturation. Further investigations of the function of Pod1 may help to determine the molecular mechanisms of tilapia sexual differentiation and gonadal development.

This work was supported by the National Natural Science Foundation of China (Grant No. 31072199) and a program of the Japan Society for the Promotion of Science, Japan.

1 Massari M E, Murre C. Helix-loop-helix proteins: Regulators of transcription in eucaryotic organisms. Mol Cell Biol, 2000, 20: $429-440$

2 Hidai H, Bardales R, Goodwin R, et al. Cloning of capsulin, a basic helix-loop-helix factor expressed in progenitor cells of the pericardium and the coronary arteries. Mech Dev, 1998, 73: 33-43

3 Lu J, Richardson J A, Olson E N. Capsulin: A novel bHLH transcription factor expressed in epicardial progenitors and mesenchyme of visceral organs. Mech Dev, 1998, 73: 23-32

4 Quaggin S E, Vanden Heuvel G B, Igarashi P. Pod1-1, a mesoderm-specific basic-helix-loop-helix protein expressed in mesenchy$\mathrm{mal}$ and glomerular epithelial cells in the developing kidney. Mech Dev, 1998, 71: 37-48

5 Quaggin S E, Schwartz L, Cui S, et al. The basic-helix-loop-helix protein Pod1 is critically important for kidney and lung organogenesis. Development, 1999, 126: 5771-5783

6 Lu J, Chang P, Richardson J A, et al. The basic helix-loop-helix transcription factor capsulin controls spleen organogenesis. Proc Natl Acad Sci USA, 2000, 97: 9525-9530

7 Miyagishi M, Nakajima T, Fukamizu A. Molecular characterization of mesoderm-restricted basic helix-loop-helix protein, Pod1-1/ Capsulin. Int J Mol Med, 2000, 5: 27-31 
8 Cui S, Schwartz L, Quaggin S E. Pod1 is required in stromal cells for glomerulogenesis. Dev Dyn, 2003, 226: 512-522

9 Funato N, Ohyama K, Kuroda T, et al. Basic helix-loop-helix transcription factor epicardin/capsulin/Pod1-1 suppresses differentiation by negative regulation of transcription. J Biol Chem, 2003, 278: 7486-7493

10 Plotkin M, Mudunuri V. Pod1 induces myofibroblast differentiation in mesenchymal progenitor cells from mouse kidney. J Cell Biochem, 2008, 103: 675-690

11 TamuraM, Kanno Y, Chuma S, et al. Pod1-1/Capsulin shows a sexand stage-dependent expression pattern in the mouse gonad development and represses expression of Ad4BP/SF-1. Mech Dev, 2001, 102: $135-144$

12 Cui S, Ross A, Stallings N, et al. Disrupted gonadogenesis and male-to-female sex reversal in Pod1 knockout mice. Development, 2004, 131: 4095-4105

13 Hong C Y, Gong E Y, Kim K, et al. Modulation of the expression and transactivation of androgen receptor by the basic helix-loop-helix transcription factor Pod1-1 through recruitment of histone deacetylase 1. Mol Endocrinol, 2005, 19: 2245-2257

14 Barsoum I B, Yao H H. Fetal leydig cells: progenitor cell maintenance and differentiation. J Androl, 2010, 31: 11-15

15 Kobayashi T, Kajiura-Kobayashi H, Guan G, et al. Sexual dimorphic expression of DMRT1 and Sox9a during gonadal differentiation and hormone-induced sex reversal in the teleost fish Nile tilapia (Oreochromis niloticus). Dev Dyn, 2008, 237: 297-306

16 Simrick S, Massé K, Jones E A. Developmental expression of Pod 1 in Xenopus laevis. Int J Dev Biol, 2005, 49: 59-63

Open Access This article is distributed under the terms of the Creative Commons Attribution License which permits any use, distribution, and reproduction in any medium, provided the original author(s) and source are credited. 